\title{
Facilitating "Paguyuban Batik Tulis Langensari" In Determining Targets To Respond The Global Fashion Trends
}

\author{
Tutun Seliari \\ Department of Architecture, Duta Wacana Christian University, Yogyakarta \\ tutunseliari@staff.ukdw.ac.id
}

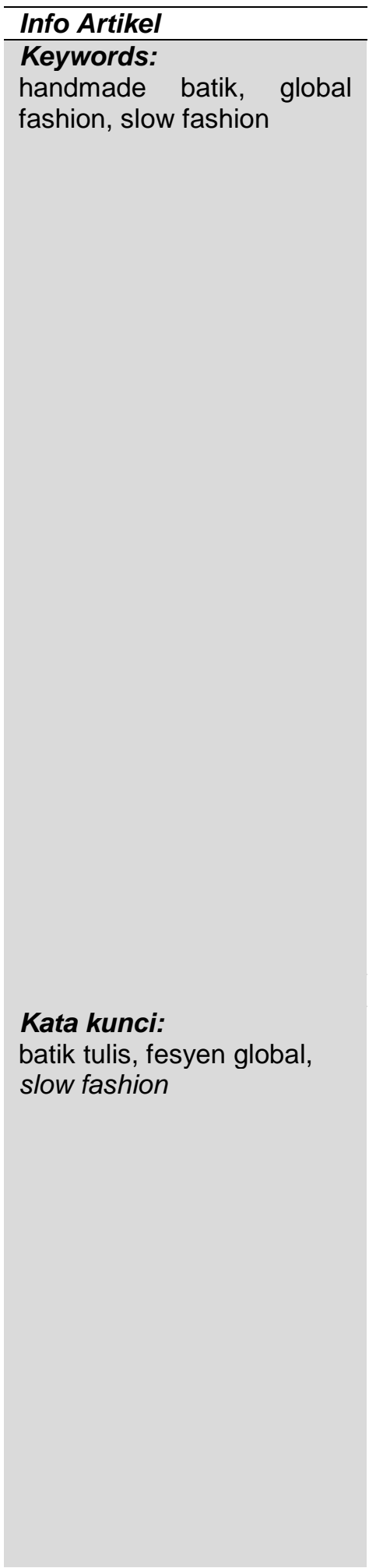

\begin{abstract}
Paguyuban Batik Tulis Langensari (PBTLS) is a community of batik artisans in the area around Embung Langensari, Yogyakarta. Determining the target of enthusiast of handmade batik from PBTLS crafters requires a strategy so that batik results can be right on target. The strategy that will be carried out requires an agreement that becomes a joint agreement in the community, given the current fashion trends that are developing very fast. Along with the development of the main trends in life, namely go green that returns to nature, fashion trends are also following. Today's global fashion trends are shifting from fast fashion to slow fashion. The target of the PBTLS is to determine the meeting point between products that have been produced as supply and market needs/demand. The method used in determining PBTLS targets is carried out through 4 stages. The first stage identifies the range of products that have been produced by PBTLS. The second stage determines the target users of PBTLS products. The third stage determines the direction of product development. Then the fourth step determines the uniqueness of PBTLS products. In carrying out these four steps, a crafter's poll was conducted through a "mentimeter application" conducted on 17 PBTLS artisans and focus group discussions (FGD). Through the application of the "mentimeter" the results of the PBTLS artisans poll can be immediately known to be discussed and formulated together through the FGD. The results obtained by the main target of PBTLS are middle-aged mothers consumers. Uniform fashion / formal batik fashion becomes the main target for the direction of PBTLS product development by developing the unique PBTLS products namely motifs and colors of handmade batik.
\end{abstract}




\begin{abstract}
Selanjutnya tahap keempat menentukan keunikan produk PBTLS. Dalam melakukan empat langkah tersebut dilakukan jajak pendapat perajin melalui "aplikasi mentimeter" yang dilakukan terhadap 17 orang perajin PBTLS dan focus group discussion (FGD). Melalui "aplikasi mentimeter" hasil jajak pendapat perajin PBTLS bisa langsung diketahui untuk dibahas dan dirumuskan bersama melalui FGD. Hasil yang didapatkan target utama dari PBTLS adalah konsumen ibu-ibu paruh baya. Busana seragam / busana resmi batik tulis menjadi target utama untuk arah pengembangan produk PBTLS dengan mengembangkan keunikan produk PBTLS yaitu motif dan warna batik tulis.
\end{abstract}

\title{
PENDAHULUAN
}

Era MEA (Masyarakat Ekonomi Asean) membawa harapan dan peluang yang sangat besar bagi perekonomian Indonesia. MEA terintegrasi dengan pasar global. Indonesia diharapkan dapat memanfaatkan semua potensi untuk meningkatkan kondisi perekonomian bangsa. Salah satu potensi Indonesia adalah indutri kreatif (Alghofari, Nandiroh, Wardhani. 2016). Salah satu kekuatan ekonomi Indonesia adalah UMKM. Peningkatan Daya saing UMKM diperlukan untuk dapat menembus pasar ASEAN dan global.

Yogyakarta dinobatkan oleh World Craft Council (WCC) sebagai World Batik City (Kota Batik Dunia) sejak 2014. Mempertahankan predikat tersebut diperlukan dukungan dari semua pihak tidak hanya dari pemerintah tetapi juga dari akademisi, swasta, masyarakat, dan stake holder lainnya. Paguyuban Batik Tulis Langensari (PBTLS) merupakan salah satu komunitas perajin batik tulis pewarna alam yang berada di Kota Yogyakarta, tepatnya di sekitar kawasan Embung Langensari. PBTLS terbentuk sejak 2015 dan saat ini sudah beranggotakan 25 orang. Hingga saat ini PBTLS konsisten dengan hasil produknya yang berupa batik tulis pewarna alam namun masih terkendala dengan pemasaran produk. PBTLS memerlukan dukungan dari berbagai pihak agar hasil produknya dapat menembus pasar global. Sejak 2018, melalui Tim PkM Batik UKDW Fakultas Arsitektur dan Desain UKDW mendampingi pengembangan komunitas PBTLS. Pada tulisan ini merupakan salah satu bagian dari rangkaian pendampingan yang telah dan sedang dilakukan kepada PBTLS.

Menetukan sasaran target penikmat batik tulis hasil karya perajin PBTLS memerlukan strategi agar batik yang dihasilkan dapat tepat sasaran. Strategi yang akan dilakukan perlu kesepakatan yang menjadi kesepakatan bersama dalam komunitas, mengingat saat ini tren fesyen yang berkembang sangat cepat. Seiring dengan perkembangan tren utama dalam kehidupan yaitu go green yang kembali ke alam, tren fesyen pun juga mengikuti. Sebuah gagasan tentang 'triple bottom line' yang mempertimbangkan people, planet, profit, merupakan sebuah pemikiran untuk mencapai sebuah keseimbangan yang berkelanjutan (Niinimaki,2013). Desain berkelanjutan yang memperhatikan dampak lingkungan dan sosial dapat diwujudkan dalam sebuah fasyen yang ramah lingkungan.

Tren fesyen global saat ini mulai bergeser dari fast fashion menjadi slow fashion. Fast fashion yang dimaksud adalah penggunaan material utama fashion dalam hal ini kain yang diproduksi secara cepat dan masal. Sedangkan yang dimaksud slow fashion adalah proses pembuatan kain yang membutuhkan keterampilan sang pembuat dan waktu yang lebih lama. Menurut Murwanti (2017), keahlian pengrajin tekstil tradisional yang diturunkan oleh nenek moyang kita dapat dirujuk sebagai praktik slow fashion. Pengetahuan atas slow fashion dianggap sebagai sebuah peninggalan budaya, sebuah warisan, dan di jamannya merupakan aktivitas sehari-hari. Sehubungan dengan teknik, proses dan materialnya, praktik slow fashion bukanlah sesuatu yang tak lazim di Indonesia karena sebagian besar praktik tekstil tradisionalnya memakan waktu yang lama untuk mencapai kualitas visual serta fungsional. Batik tulis pewarna alam merupakan salah satu karya produk slow fashion.

Saat ini tren fesyen global selain kembali ke alam juga mengarah ke budaya lokal. Batik tulis pewarna alam sebagai salah satu alternatif material kain dalam industri fesyen pun juga mengalami perkembangan. Sebagai bagian dari budaya lokal, batik mempunyai daya tawar dan daya saing yang sangat baik. Berdasarkan motif dan warnanya batik dapat dikategorikan menjadi dua kategori, yang pertama merupakan batik klasik yang mempunyai pakem terutama pakem terhadap tradisi, sedangkan yang kedua merpakan batik kontemporer/pop yang mempunyai perkembangan motif dari motif-motif batik klasik dan variasi warna yang lebih beragam. Pendampingan yang dilakukan 
terhadap PBTLS pada kesempatan ini bertujuan untuk mendapatkan strategi-strategi sehingga produk-produk PBTLS mampu bersaing dalam tren pasar global.

\section{BAHAN DAN METODE}

Metode yang dilakukan dalam menentukan target PBTLS dilakukan pelatihan kepada para perajin PBTLS. Penentuan target dilakukan melalui 4 tahap. Tahap pertama mengidentifikasi ragam produk yang sudah dihasilkan oleh PBTLS. Tahap kedua menentukan sasaran pengguna dari produk PBTLS. Tahap ketiga menentukan arah pengembangan produk. Selanjutnya tahap keempat menentukan keunikan produk PBTLS. Dalam melakukan empat langkah tersebut dilakukan jajak pendapat perajin melalui aplikasi mentimeter secara online yang dilakukan terhadap perajin PBTLS dilanjutkan dengan focus group discussion (FGD). Untuk melakukan jajak pendapat melalui mentimeter diperlukan smart phone yang terkoneksi dengan jaringan internet bagi masing-masing peserta, dan satu proyektor LCD untuk menampilkan hasil jawaban dari jajak pendapat sehingga bisa dilihat langsung secara bersama. Melalui aplikasi mentimeter hasil jajak pendapat perajin PBTLS bisa langsung diketahui untuk dibahas dan dirumuskan bersama melalui diskusi / FGD.

\section{HASIL DAN DISKUSI}

Melihat perkembangan tren fesyen global, komunitas PBTLS merespon hal tersebut sebagai bagian dari sisi demand. Target dari PBTLS adalah menentukan titik temu antara produk-produk yang sudah dihasilkan sebagai supply (penawaran) dan kebutuhan pasar I demand (permintaan). Kebutuhan pasar yang sangat beragam perlu diidenttifikasi mana saja yang akan dijadikan segmen terpilih untuk menjadi target pasarnya. Slow fashion tetap menjadi konsep utama bagi perajin di PBTLS karena lebih ramah lingkungan dan melestarikan kebudayaan lokal. Walaupun saat ini masih banyak pembuatan batik yang menggunakan pewarna sintetis, PBTLS tetap konsisten untuk menggunakan pewarna alam untuk hasil produk batik tulisnya.

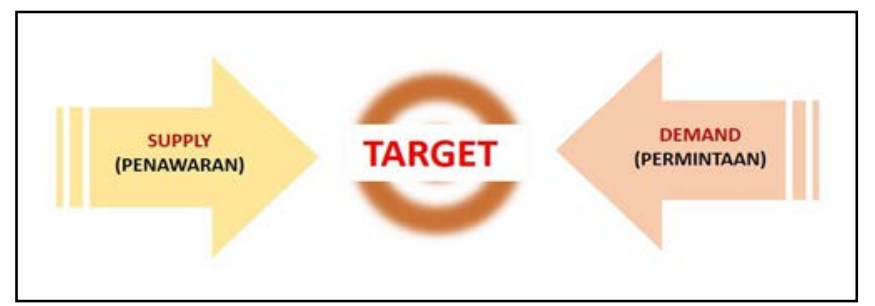

Gambar 1. Skema Target Komunitas PBTLS

Sumber : Dokumen Tim Batik Langensari (2019)

Sebagai langkah awal, komunitas mengidentifikasi ragam produk yang sudah dihasilkan oleh PBTLS. Ragam produk yang sudah dihasilkan berupa kain lembaran dan olahannya, antara lain taplak, pashmina, syal, baju, tas, bed cover dan sprei. Dapat dilihat dari hasil jajak pendapat para perajin bahwa sebagian besar hasil produk yang dihasilkan masih berupa kain lembaran, hanya baju dan tas yang sudah diolah menjadi produk turunan. Dari hasil identifikasi produk-produk yang dihasilkan tersebut, Tim PkM dan para perajin melakukan brain storming melihat peluang pasar yang ada saat ini. Berdasarkan permintaan pasar yang mulai beragam dan tidak hanya berupa kain lembaran, komunitas PBTLS sepakat untuk mengembangkan hasil produknya untuk mendapatkan diversifikasi produk yang lebih beragam sehingga jangkauan pasar menjadi lebih luas. Selain olahan dari produk kain lembaran itu sendiri komunitas PBTLS juga akan diversifikasi produk dengan memadukan kain batik tulis pewarna alam dengan material lain, misalnya dengan kulit, kain tenun, dan dari jenis kain lainnya. Perca kain sisa olahan juga akan dimanfaatkan untuk mengurangi limbah dan menerapkan prinsip circular economy.

Langkah kedua yang dilakukan adalah menentukan sasaran pengguna dari produk PBTLS. Berdasarkan ragam produk yang dihasilkan dan jajak pendapat melalui aplikasi mentimeter yang dilakukan terhadap 17 orang perajin PBTLS, Ibu-lbu separuh baya merupakan pengguna terbanyak yang membeli dan menggunakan produk PBTLS. Pembeli dan pengguna selanjutnya adalah ibu-ibu 
muda dan anak muda. Berdasarkan penjelasan saat diskusi yang dilakukan saat pelatihan, secara spesifik konsumen anak muda adalah remaja/pemudi putri.

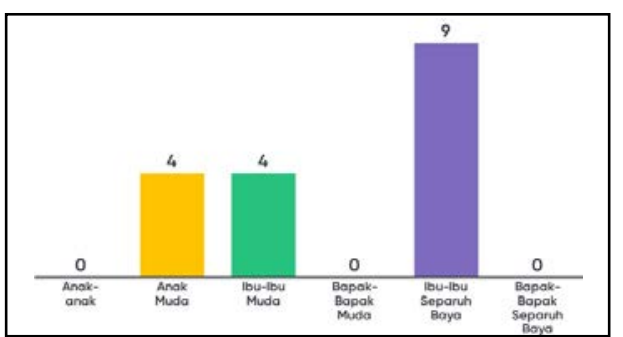

Gambar 2. Diagram Pembeli dan Pengguna Produk PBTLS

Sumber : Dokumen Tim Batik Langensari(2019)

Sehingga berdasarkan Gambar 2, pembeli dan pengguna produk PBTLS dapat disimpulkan bahwa pembeli dan pengguna sebagian besar adalah perempuan. Laki-laki belum menjadi target utama dari komunitas PBTLS untuk dijadikan konsumen utama.

Langkah yang ketiga adalah melakukan jajak pendapat terhadap arah pengembangan produk fesyen yang dihasilkan PBTLS. Selain diversivikasi produk turunan dari kain batik tulis, untuk merambah ke dunia fesyen, PBTL mempunyai arahan untuk mengembangkan fesyen ke seragam karena saat ini produk fesyen yang banyak dihasilkan oleh PBTLS adalah kain lembaran untuk seragam.

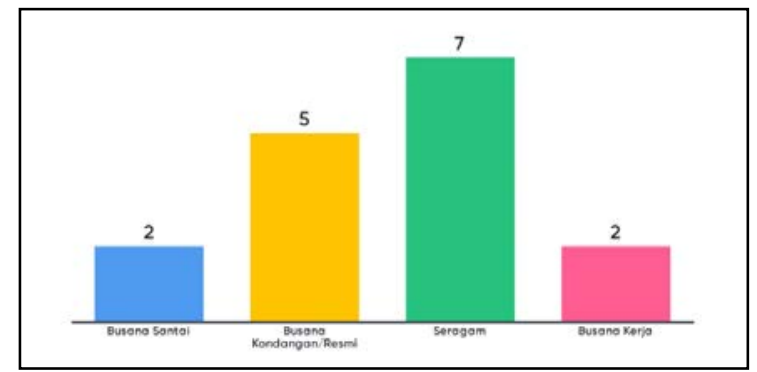

Gambar 3. Arahan Produk PBTLS

Sumber : Dokumen Tim Batik Langensari(2019)

Arahan pengembangan produk fesyen berikutnya adalah busana resmi, dan selanjutnya busana kerja dan santai. Busana seragam dan busana resmi menjadi target utama arah pengembangan produk PBTLS karena saat ini produk PBTLS lebih banyak berupa batik tulis klasik yang biasa digunakan untuk seragam dan busana resmi.

Langkah yang keempat menentukan keunikan dari PBTLS. Berdasarkan hasil jajak pendapat kepada para perajin batik tulis pewarna alam yang dihasilkan oleh PBTLS mempunyai keunikan dari aspek motif dan warna. Hal yang perlu diperhatikan untuk tetap mempertahankan dan membuat keunikan bagi produk PBTLS antara lain adalah memperhatikan kompetitor, ide yang out of the box, implementasi yang memerlukan kesabaran konsistensi, dan diperlukan evaluasi secara berkala. Motif dan warna, dua aspek ini akan dikembangkan menjadi keunggulan dari produk PBTLS agar memiliki daya saing. Motif yang khas terhadap keberadaan dan eksistensi PBTLS karena lokasinya di sekitar Embung Langensari dan penggunaan warna alam yang soft / lembut mempunyai kesan teduh.

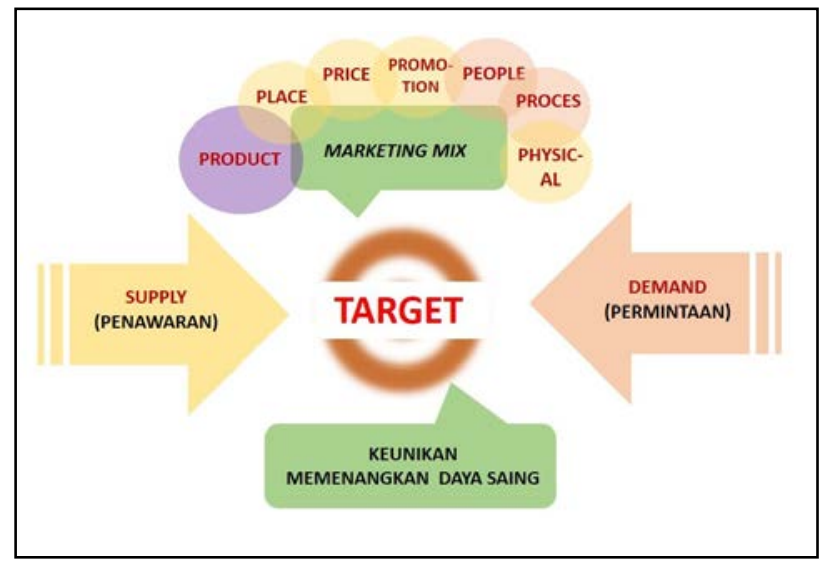




\author{
Gambar 4. Skema Strategi \\ Sumber : Dokumen Tim Batik Langensari(2019)
}

Gambar 4. merupakan langkah strategi yang dilakukan PBTLS untuk memperoleh kesepakatan dan kekompakan komunitas dalam menentukan target pasar bagi produk yang dihasilkan PBTLS. Prinsip marketing mix juga diterapkan dalam penentuan target.

Kendala yang didapatkan saat pelatihan dalam rangka pendampingan kepada PBTLS dalam menentukan target pasar, dengan menggunakan metode mentimeter dan FGD ini adalah tentang kebutuhan waktu. Perajin yang menjadi peserta pelatihan sebagian besar adalah ibu-ibu separuh baya, walaupun sudah terbiasa menggunakan smart phone dan sering mengakses media sosial namun ketika menggunakan aplikasi ini karena baru pertama kali sehingga sebagian besar masih canggung dan belum terbiasa sehingga membutuhkan waktu untuk berlatih. Namun ketika hasil jajak pendapat bisa langsung diketahui bersama hal ini menjadi sebuah kejutan dan seluruh peserta menjadi tertarik sehingga kegiatan pelatihan menjadi lebih menyenangkan bagi peserta. Setiap pertanyaan langsung dibahas hasilnya melalui FGD sehingga memerlukan waktu yang cukup lama karena untuk setiap pertanyaan memnacing ide-ide dan pemikiran baik dari masing-masing peserta maupun tim pendamping PkM.

Langkah yang didapatkan untuk menentukan target pasar produk PBTLS adalah tahap pertama mengidentifikasi ragam produk yang sudah dihasilkan oleh PBTLS. Identifikasi produk yang dihasilkan saat ini sebagian besar berupa kain lembaran dan akan dikembangangkan diversifikasi produknya menjadi produk turunan berupa kain olahan dan kombinasi dengan material lainnya. Tahap kedua menentukan sasaran pengguna dari produk PBTLS. Perempuan merupakan target utama dari PBTLS terutama ibu-ibu separuh baya dan Ibu-ibu muda. Tahap ketiga menentukan arah pengembangan produk. Produk yang banyak dihasilkan PBTLS adalah kain lembaran sehingga arahan pengembangan produk fesyen lebih kearah busana resmi dan busana kerja. Selanjutnya tahap keempat menentukan keunikan produk PBTLS. Motif dan warna merupakan keunikan dari produk PBTLS. Motif yang dikembangkan khas dengan alam berupa embung dan flora dengan warna yang soft dan teduh yang dihasilkan dari pewarna alam.

Dari uraian diatas strategi dalam menentukan target PBTLS dalam merespon tren fasyen global adalah dengan mengidentifikasi keragaman produk yang sudah dihasilkan, melihat permintaan yang ada di pasar, menentukan keunikan dari produk PBTLS, dan menkolaborasikan dengan prinsip marketing mix dalam menentukan target. Prinsip 'marketing mix' masih perlu dikaji lebih mendalam terkait hasil produk batik tulis pewarna alam PBTLS dan akan dilakukan pada tahap pendampingan selanjutnya.

\title{
UCAPAN TERIMA KASIH
}

Terimakasih kepada seluruh keluarga besar Paguyuban Batik Tulis Langensari (PBTLS), Pemerintah Kelurahan Klitren, Fakultas Arsitektur dan Desain UKDW, LPPM UKDW, dan Tim PkM Batik UKDW : Kristian Oentoro, M.Ds dan Dr.Ing Sita Yuliastuti Amijaya, M.Eng., atas seluruh dukungan yang telah diberikan sehingga proses kegiatan PkM Batik UKDW bersama PBTLS dapat berjalan baik dan lancar.

\section{REFERENCES}

Alghofari, Ahmad Kholid, et.al. 2016. Profil Industri Kreatif Batik Bidang Fashion dan Identifikasi Value Chain di Kampung Batik Laweyan Surakarta. Prosiding Seminar Nasional IENACO - 2016, hal 211-218.

Niinimaki, Kirsi (ed). 2013. Sustainable Fashion : New Approaches. Finland : Aalto University.

Murwanti, Aprina. 2017. Slow Fashion : Sebuah buklet mengenai gerakan hijau alternative Indonesia. Indonesia : Goethe Institut.

https://www.wccinternational.org/craft-cities (diakses 4 September 2019) 